\title{
The Attributes of The Bread Store. A Case Study (a) BreadtalkIndo
}

\author{
Arissetyanto Nugroho \\ Department of Management, Universitas Mercu Buana, Indonesia
}

\begin{abstract}
Research explores the attributes of the bread store, a case study@BreadtalkIndo twitter. There is 557 tweet dataset extracted from@BreadtalkIndo; further analysis findings show there are eight themes, most of the themes related to the product, promotion, and place@BreadtalkIndo. This finding shows that @BreadtalkIndo twitter utilized for further marketing mix optimization.
\end{abstract}

Keywords: @BreadtalkIndo, Marketing Communication Attribute, Exploratory Factor Analysis

DOI: $10.7176 / \mathrm{JMCR} / 59-04$

Publication date: August $31^{\text {st }} 2019$

\section{Research Background}

$35 \%$ of the household expenditure influence the growth of the consumption sector in Indonesia (International, 2019). It is much proportion for the household expenditure. Therefore the business competition in the consumption sector is also growing. One of the business industry that is growing is the food and beverage industry.

The data show that bread, rice, and cereals contribute $25 \%$ for the food in the household expenditure (International, 2019). Bread, uniquely branded food, is also growing in the Indonesian household expenditure. Therefore, there is a need to explore the branded store in Indonesia, such as the bread store. The research will expose the growing phenomena in the Indonesian consumer market.

Many attributes influence the decision-making process. There are personality, preference, character, needs, and wants that form a combination of preference for each consumer. The combination of preference influence the decision to consume a product or services (Singh \& Kathuria, 2016). There is also a pattern that distinguishes a group of consumers compare to the others in term of the intention to buy a product or services.

The need to map and expose the pattern is necessary, especially in the bread store in Indonesia. Breadtalk is one of the recognized bread store in Singapore, which have a good position for consumer foodservice. The success in Singapore follows the success in Indonesia. There are more than 35 Breadtalk stores all over Indonesia that grow from 2003. This significant growth of the Breadtalk is the background of the research to explore the BreadtalkIndo service proposition to the targeted market.

Table 1. Breadtalk Competitive Position

\begin{tabular}{|l|r|r|}
\hline Summary 3 Breadtalk Pte Ltd: Competitive Position 2016 & & \\
\hline Product type & Foodservice value share & Rank \\
\hline Consumer foodservice & $1.80 \%$ & 3 \\
\hline $100 \%$ home delivery/takeaway - - & $1.30 \%$ & 3 \\
\hline Cafés/bars & $5.10 \%$ & 1 \\
\hline Full-service restaurants & $0.40 \%$ & 16 \\
\hline Fast food & & \\
\hline Self-service cafeterias -- & & \\
\hline Street stalls/kiosks & & \\
\hline- & & \\
\hline $\begin{array}{l}\text { Source: Euromonitor International from company reports, company } \\
\text { research, trade press, trade sources, trade interviews }\end{array}$ & \\
\hline
\end{tabular}

\section{Source: Euromonitor 2017}

Breadtalk selected as the case study since Breadtalk founded in 2000 in Singapore. Breadtalk ranked third in a competitive position in Singapore for consumer foodservice (Euromonitor, 2017). Dr. George Quek is the founder of the bread Talk that succeeding the company that employs 6000 employees. This success followed with Johnny Andrean decision to open a franchise of Bread Talk in Indonesia in 2003. The first store is in Mall Kelapa Gading Jakarta, and since then, there are 73 stores distributed all over Indonesia. Therefore the research aimed to explore the@BreadtalkIndo proposition toward the targeted market.

\section{Theoretical Review}

The consumer preference to choose products and services are different between one consumer and the other. Every consumer has their own needs and wants; the preferences form a set of combination that influences the 
decision-making process to buy a product or service (Singh \& Kathuria, 2016). It is interesting to explore the preference of consumers to buy a piece of bread. The consumer lifestyle to buy a branded bread are different compared to the previous era. In the previous era the family buying bread from the seller that crossing their house.

Bread also consider as a portion of important food, and substitution for breakfast. Bread is also the choice of food when the consumer wants to have a snack between breakfast, lunch, and dinner. Bread also considered as the food when the consumer is going to have activities like a birthday, anniversary; therefore there are a growing needs for bread in Indonesia (Rahmawaty, 2015) (Ali \& Ryu, 2015).

The consumption of bread is part of the lifestyle of the people in urban cities. Bread considered simple, practical, and straightforward food to consume. People have to buy the bread, and they could take the bread in a package to elsewhere. It did not stale very fast; therefore, there is practicality for choosing bread as a substitution for rice and noodles. Bread is also a substitution for regular food at lunch, dinner, and breakfast, a substitution for regular food consumption. Therefore it is reasonable to see that bread is the essential food choices after rice and noodle.

One of the branded bread stores in Indonesia is Breadtalk. The brand is an international franchise that presents a modern bakery, and an open kitchen store concept with an open display that engages the consumer to choose the product and also see the process of the bread-making in the store (Euromonitor, 2017). The consumer can see the high tech baking machine that they use to produce the bread. Moreover, since they have this open store on site, therefore, the consumer and the environment could also smell the flavor of the bread (Suyanto \& Yurdatila, 2013). The system to convince the consumers to buy the Breadtalk product.

\section{Research Method}

The data processing start with data preparation to take out the double posted data (Figure 1). Furthermore, after the data prepared, and then analyzed for further process. The process conducted is an exploratory factor analysis with the research software that will show the insight of this 557 unstructured dataset into a few themes that easy to interpret.

\begin{tabular}{|c|c|c|c|}
\hline $\begin{array}{l}\text { Data Extraction } \\
\text { @BreadtalkIndo }\end{array}$ & Data Preparation & $\begin{array}{c}\text { Exploratory Factor } \\
\text { Analysis }\end{array}$ & Findings \& Discussion \\
\hline 557 Dataset & $\begin{array}{l}383 \text { Tweet \& } \\
174 \text { ReTweet }\end{array}$ & 8 Themes & \begin{tabular}{|c} 
Product, Promotion \& \\
Place
\end{tabular} \\
\hline
\end{tabular}

Figure 1. Research Process

An exploratory factor analysis look for relationship within the dataset (Wijanto, 2008). The research is looking for specific relationship within the data (Hair, Anderson, Tatham, \& William, 1998). Exploratory factor analysis conducted since there is still a lack of theory related to the bread store proposition. Therefore the twitter data set are relevant to explore the bread store attribute. The exploratory factor analysis method conducted in the airline (Sihite \& Nugroho, 2017), hospitality (Nugroho, 2018) (Nugroho, Sihite, \& Harwani, 2019), kitchen appliances (Sihite, 2019b), National Tourism Organization (Nugroho \& Sihite, 2018) (Sihite \& Nugroho, 2018) (Nugroho, 2017), online transportation (Sihite, 2019a), political marketing (Sihite, Assauri, \& Halim, 2018), University (Nugroho \& Sihite, 2015a) (Nugroho \& Sihite, 2015b), Syariah Bank (Nugroho \& Sihite, 2016), and coffee shop (Harwani \& Sihite, 2019).

The cluster analysis technique process the textual dataset. The cluster analysis will reduce the unstructured dataset into selected themes. Reduce the data complexity into few dimension (Campbell, Pitt, Parent, \& Berthon, 2011). The Provalis Research Software selected for the cluster analysis, to identify the keywords and also the relationship between keywords with the co-occurrence method (Silver \& Lewins, 2014).

\section{Results and Discussion}

The research exposed information about a bread store brand that is popular in Indonesia, which is Breadtalk. There are many inputs, critics, a suggestion, promotion, and also question delivered from the customer to the twitter@BreadtalkIndo. They are asking about the quality, services, and the taste of the Breadtalk.

Moreover, 5 July 2017, @BreadtalkIndo delivering information about the promotion of the service for delivery that beneficial for the buyer to buy bread talk. @BreadtalkIndo Indonesia Twitter state, "hungry? You do not eager to go out of your house? Let us call the delivery services of your favorite bread store, btdelivery.com, or you could call 1-500-377.

The next promotion on October 11,2017, by the account @BluPlazaBKS is delivering information to the customer about the@BreadtalkIndo promotion. The promotion relates to all selected discounted bread. The Twitter state let us get the promotion from@BreadtalkIndo in the Blu Plaza Bekasi. All bread is 7500 rupiah, sliced cake 18,000, cookies and roll cake 51,000, whole cake 119,000 rupiahs. @BluPlazaBKS is the Twitter account of Plaza Bekasi that are giving a discount because Breadtalk opens a new store in the mall. 
Another promotion delivered on 17 December 2017,@BreadtalkIndo cooperating with@grabID delivering a Breadtalk voucher for the amount of 25,000 rupiahs. This promotion is for the Grab application user; the consumer could redeem the voucher in the application. The tweet said that connect and redeem your points in the Grab reward for a Breadtalk voucher for 25,000 rupiahs. For more information please open the application at @GrabID and click the Grab rewards Breadtalk voucher, and then click purchase. The promotion will be available until 1 March 2018. Requirements and also for the regulation applied.

Furthermore, Breadtalk also arranging a Breadtalk fiesta 2017 to celebrate the 14th anniversary. On 9 October 2017, the account a@mallbekasi is delivering information that asked the consumer to come and celebrate the Breadtalk fiesta 2017. The event will be available for the public from 11 until 12 October 2017. All bread price is RP 7500, and it is applied in Bradtalk on the ground floor. Since there is an event of Breadtalk fiesta to celebrate the 14th anniversary, they are making an event of promotion discount for two days only in the selected store.

The netizen is also delivering a complaint. On 09 February 2017, there is a complaint from customers about the quality of the bread that is not good. The customer said that the bread is overcooked. @Maureenaubrey tweeting, I am buying the bread in the Kokas outlet, but I realize when I have my breakfast that The Breadtalk is overcooked. Breadtalk replying the account and said that they are sending an apology and will follow up the problems. Here is the reply from the@BreadtalkIndo. Dear@Maureenaubrey, we are apologizing for the problems. Please send us your phone number so we could call and also follow up this matters. Thank you.

Another complaint from @Niniek_11 on 11 October 2017 saying the service delivered by the Breadtalk is not satisfying, because the EDC machine not available. The tweet delivered to @BreadtalkIndo, on 10 October, I have a transaction in the PGC counter and Kalibata with my e-money, but it is not available. The EDC is not working.

@ BreadtalkIndo are replying to the complaint and asking for an apology and asking the customer phone number to follow up the problem. Here is the reply, dear customer, we are sending an apology for the inconvenience. Please inform your phone number so we could follow up on the problem. The tweet is saying that they are doing a transaction in PGC, but when they want to use a debit card, the machine is broken.

It is not only a critic but also inputs from the Breadtalk customer. A customer on 14 October 2017 from the account@tomiPantsu are delivering a tweet about the cleanliness of the bread talk store. @tomiPantsu say that @BreadtalkIndo should improve the cleanliness of the bread talk living world, there are many flies on the bread. Moreover, the Breadtalk replying to the complaint and delivering a thank you gratitude and promised to improve the cleanliness of the store.

Another input for@BreadtalkIndo on 13 March 2017 from the account@akuheidi,@akuheidi is delivering a comment with the photographs that show a place that needs to be cleaner.@akuheidi saying that in the Pasar Festival outlet there are flies in the outlet. Moreover, in the cashier, there is a little cockroach.

Hygiene factor is an important thing, the account@BreadtalkIndo state, dear Maria, thank you for your input. We will follow up these matters because the outlet did not have excellent sanitary and clean. Therefore the bread cleanliness is also questioned.

On25 April $2017 @$ bas_lolo complaining about the delivery services from the Breadtalk. The tweet said that he/she is disappointed about the delivery services @BreadtalkIndo. The birthday cake is damaged, and they are disappointed. I hope this is not going to be happening in another customer. The complaint will be a useful input for the Breadtalk to improve the services. Breadtalk answering the complaint with Dear@bas_lolo, sorry for the problems. We will consider this as our input to improve our services for the customer.

On 22 August 2017, there is a customer that is delivering a question related to the information because the customer confuses for the instruction to buy a cake at $@$ BreadtalkIndo. The tweet said that could the red velvet cake for the $16 \mathrm{~cm}$ directly purchased, or should we order it first? The information related to the process to order the cake from@madridswhite.@madridswhite responded the@BreadtalkIndo by replying, hello you could buy it directly in the store.

There is also a customer that still not sure about the Halal of the bread talk bread. Therefore there is a question on9 December 2017 from@jilbabmenx and@zazachan. They are asking a question@BreadtalkIndo, do you have a Halal certificate from MUI? The question directly responded by the @BreadtalkIndo that all of the ingredients are halal and did not use ingredients contain alcohol, pork, and also other non-halal ingredients this statement clarifying that the question regards to the Halal of the Breadtalk product.

The next question comes from a customer@azkasan18 that are still confused about how to order a birthday cake. On 16 December 2017, @azkasan18 asking whether the cake could be delivered directly to the person that has an anniversary, and the person is different from the one that ordered the cake. Moreover, whether the payment applied by transfer, not by cash?. Moreover, then@BreadtalkIndo bring an explanation that you could do as you wish and for more information, you could call the Breadtalk delivery call services in 021-1500-377.

A customer is sending an appreciation @BreadtalkIndo. Appreciation delivered by @rusydina_11 on 23 January that said the Breadtalk is the favorite dessert. In the same day the customer with the account 
(a) dewisapril saying that the flavor of the bread is unique. There is also a customer from the 17 February with the discount@cintanoverine saying that all the bread is@contanovetine favorite. There are also much appreciated that the customer delivers to the Breadtalk.

$$
\text { BreadTalkindo }
$$

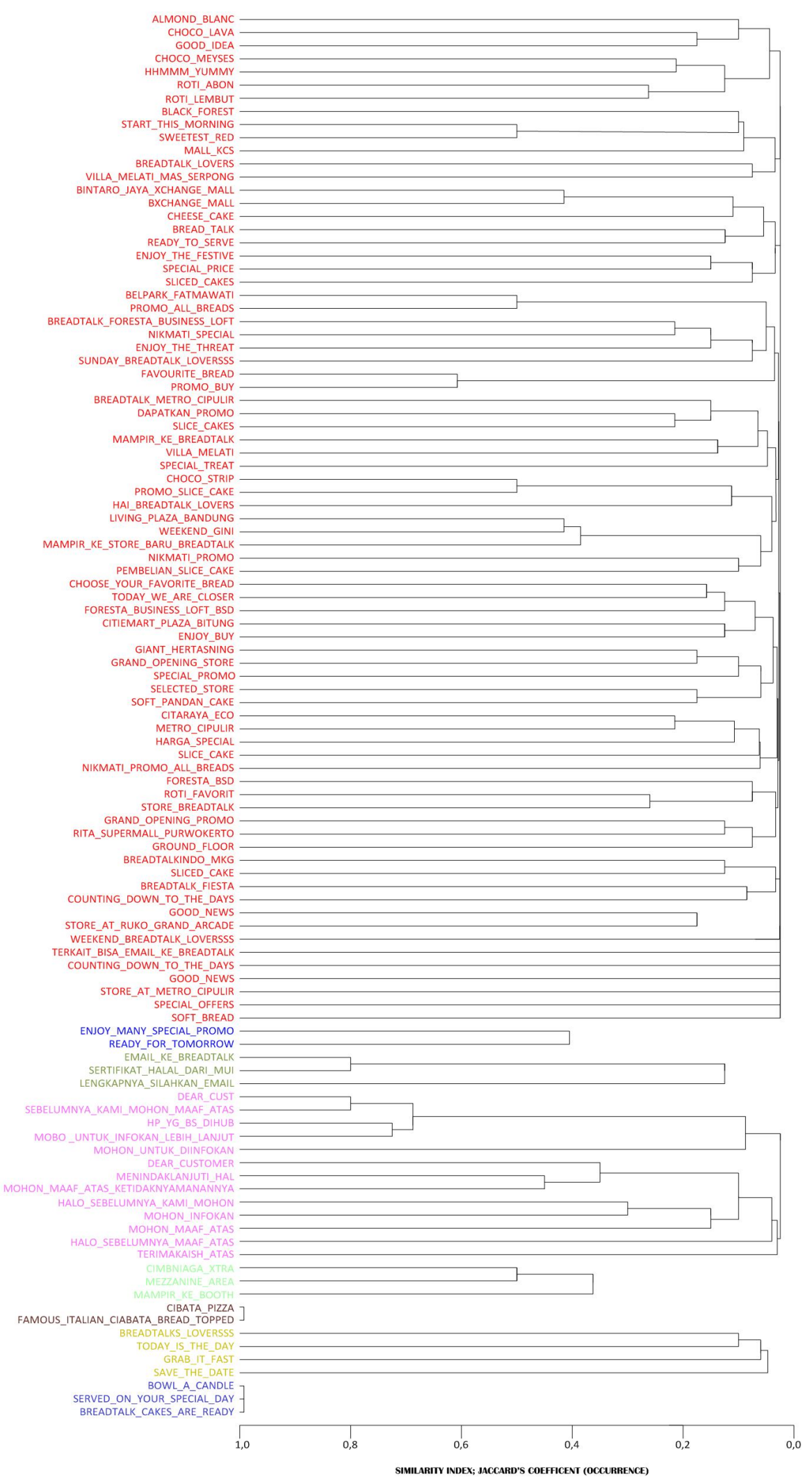

Figure 2. Dendrogram @BreadtalkIndo 


\section{Conclusion}

From the research, we could conclude that at @BreadtalkIndo delivering the basic elements of the marketing mix. They are delivering a marketing communication, promoting the product, and also delivering information about the place for Breadtalkstore.

The interesting is at @BreadtalkIndo answering complaints from the consumers, such as informing the consumer how to order the bread, the payment instructions, and also related to the products and services information. Informing there is a new Breadtalk store, answering a complaint from the consumers, such as informing the consumer how to order the bread, the payment instructions, and also related to the products and services information.

Since there is a new Breadtalk store, @,BreadtalkIndo also delivering information related to the place, the cleanliness of the stores and also the services to deliver the Breadtalk. Breadtalk is also assisting the consumers for a real-time transaction payment via transfer or cash. The process of this transaction highly related to the consumer process to order and receive the Breadtalk. Therefore the process supported with the information from the@BreadtalkIndo, that result of satisfaction of the consumers not just when consuming the product, but it starts from browsing and also asking information related to the product.

@BreadtalkIndo is also improving the way of communicating to the public and engage to the consumers. This two way of communication is important to maintain a good relationship quality with the consumers. Therefore, the researchers conclude that @Breadtalk store is delivering a variety of attributes of the marketing mix element@BreadtalkIndo in a way that is beneficial to improve the effectiveness of the marketing mix strategy.

\section{References}

Ali, F., \& Ryu, K. (2015). Bringing them back to spend more: student foodservice experiences to satisfy their taste buds. Young Consumers, 16(2), 235-248.

Campbell, C., Pitt, L. F., Parent, M., \& Berthon, P. (2011). Tracking Back-Talk in Consumer-Generated Advertising: An Analysis of Two Interpretative Approaches. Journal of advertising research, 51(1), 224. doi:10.2501/jar-51-1-224-238

Euromonitor. (2017). BreadTalk Pte Ltd in Consumer Foodservice (Singapore).

Hair, J. F., Anderson, R. E., Tatham, R. L., \& William, C. (1998). Multivariate data analysis.

Harwani, Y., \& Sihite, J. (2019). The Marketing Mix Element of the Coffee Shop. A Case Study (a)CoffeeBeanIndo. European Journal of Business and Management, 11(18), 169-174. doi:10.7176/EJBM/11-18-20

International, B. M. (2019). Indonesia Food \& Drink Report.

Nugroho, A. (2017). ASEAN Tourism Marketing Communication Attribute: An Exploratory Research at Goaseantv. European Research Studies Journal, XX(3).

Nugroho, A. (2018). The Hospitality Marketing Communication Attribute. A Case Study@ @hrhbali (Hard Rock Hotel Bali). Journal of Marketing and Consumer Research, 50.

Nugroho, A., \& Sihite, J. (2015a). Is It A Relational Marketing Strategy? Cluster Analysis (a) Universitasmercubuanajakarta Facebook Post and Comment. Manajemen MIX, V(2).

Nugroho, A., \& Sihite, J. (2015b). Is It Traditional or Contemporary Marketing Strategy? A Textual Cluster Analysis@MercuBuana Reg. Mediterranean Journal of Social Sciences, VI(5).

Nugroho, A., \& Sihite, J. (2016). Exploratory Factor Analysis Syariahmandiri and Bankmandiri Service Attributes 2015. . The Social Sciences, 11, 4896-4901.

Nugroho, A., \& Sihite, J. (2018). ASEAN Tourism Destination: A Strategic Plan. European Research Studies Journal, 21(3), 293-298.

Nugroho, A., Sihite, J., \& Harwani, Y. (2019). The Promotion, Product and the People of Luxurious Hotel: A Case Study@hrhbali 2018. Journal of Tourism, Hospitality and Sports, 41, 73-78. doi:10.7176/JTHS/41-01

Rahmawaty, P. (2015). Pengaruh Variasi Produk, Harga, dan Customer Experience Terhadap Keputusan Pembelian Ulang Roti BreadTalk Yogyakarta. Jurnal Ilmu Manajemen, 12(1), 89-98.

Sihite, J. (2019a). The Online Transportation Marketing Mix CoCreation: A Case Study@gojekindonesia. Journal of Marketing and Consumer Research, 57, 44-50. doi:10.7176/JMCR/57-05

Sihite, J. (2019b). The Promotion and Process Attribute for the Kitchen Appliance. A Case Study @KitchenAid_Indo. European Journal of Business and Management, 11(18), 164-168. doi:10.7176/EJBM/11-18-19

Sihite, J., Assauri, S., \& Halim, R. E. (2018). Brand Promise and Reputation Against the Campaign of a Political Party. European Research Studies, 21, 227-240.

Sihite, J., \& Nugroho, A. (2017). Brand Extension In The Marketspace Journal of Economic \& Management Perspectives, 11(3).

Sihite, J., \& Nugroho, A. (2018). Exploring the Indonesian Tourism Destination via Indonesia.Travel 
@indtravel.

Silver, C., \& Lewins, A. (2014). Using software in qualitative research: a step-by-step guide.

Singh, A., \& Kathuria, L. M. (2016). Understanding drivers of branded food choice among low-income consumers. Food quality and preference, 52, 52-61.

Suyanto, A., \& Yurdatila, F. (2013). Pengaruh Experiential Marketing Terhadap Kepuasan Dan Loyalitas Pelanggan Breadtalk Mall Kelapa Gading 3, Jakarta. JURNAL ILMU MANAJEMEN DAN BISNIS, 4(2).

Wijanto, S. H. (2008). Structural Equation Modeling dengan LISREL 8.8: Konsep dan Tutorial. 